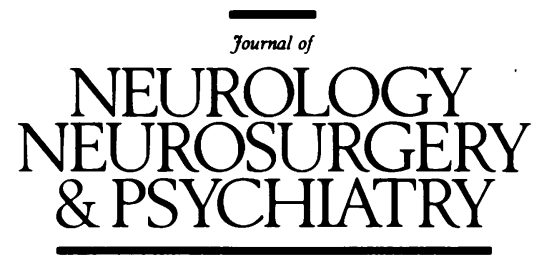

Editorial

\title{
Multiple sclerosis and the mind
}

Multiple sclerosis (MS) is a disease of the brain and the mind. Emotional changes, abnormalities of affective expression and cognitive decline have been recognised since the turn of the century but, with a few exceptions ${ }^{12}$. have been overlooked, until new imaging techniques made it possible to study brain pathology in vivo. We have learnt much about the psychiatric features and patterns of cognitive impairment and the frequency with which they occur, but the link with brain pathology has proved more elusive. The multifaceted interactions between environmental and organic factors in the causation of psychiatric and cognitive abnormalities and the fluctuations in lesion size and number, often without overt clinical manifestations, need to be better understood before the psychopathology of MS can be fully explained.

\section{Psychiatric abnormalities}

Transient mood changes, irritability and anxiety are the rule rather than the exception in MS. Two thirds of patients experience these symptoms in the course of a year and in a third they will be severe enough to merit the diagnosis of major depression. ${ }^{3} \mathrm{~A}$ life time prevalence for this diagnosis ranges from $40-50 \%{ }^{4}$ while an increased association with bipolar affective disorder has also been found. ${ }^{56}$ Fatigue, common to both MS and depression, cannot account for this increased morbidity. Transient hypomanic episodes may occur in association with steroid teatment ${ }^{7}$ and affective symptoms in general are more common during exacerbations ${ }^{8}$ and in patients with a chronic progressive course, ${ }^{9}$ but they are not closely related to the degree of physical disability. ${ }^{10} 11$ The vulnerability of MS patients to psychiatric illness is comparable to that of patients with temporal lobe epilepsy ${ }^{12}$ and much higher than in the general population ${ }^{3}$ or similarly disabled patients without brain disease. ${ }^{11}$ These facts, added to the observation that the family history and incidence of psychiatric illness before the onset of neurological symptoms are similar to those in the general population, ${ }^{13}$ argue in favour of a causal role for brain pathology. This is, however, only half of the story as psychiatric morbidity and severity of MRI abnormalities are not highly correlated, whilst the degree of stress perceived by the patient is a much better predictor of an abnormal mental state. ${ }^{11}$ This suggests an interactional model in which the vulnerability created by the presence of brain damage greatly enhances the effect of environmental factors in producing psychiatric disease.

Euphoria and eutonia, once considered to be the hallmark of $\mathrm{MS}^{14}$ only occur in about $10 \%$ of patients. Euphoria is best defined as a state of elated mood with a happy and cheerful outlook and eutonia, a milder variety of euphoria, as an apparent lack of concern about the severity and implications of the disease. These static mood changes are more akin to a personality change than to an affective disorder. The severity of brain pathology, as shown by MRI, is correlated with the presence of euphoria and eutonia. ${ }^{11}$ Pathological laughing and crying, an abnormal display of emotion without subjective mood changes, is also rare. It has been reported to be associated with the presence of pontine, brain stem $^{4}$ and periventricular lesions ${ }^{1015}$ probably causing a frontal disconnection syndrome.

Short lived psychoses with symptoms indistinguishable from schizophrenia, have been reported in MS. ${ }^{1617}$ As a rule they occur in the absence of positive family history when MS is well established and at a later age than is common for schizophrenia, thus suggesting a causal role for brain pathology. This has recently been corroborated in an MRI study carried out at the National Hospital for Neurology and Neurosurgery ${ }^{18}$ where psychotic MS patients were found to have a greater lesion load around both temporal horns than non-psychotic MS patients matched for disease characteristics.

The possibility that psychiatric abnormalities could be the first manifestation of MS has attracted far more attention than the available evidence justifies. ${ }^{1920}$ Confusional states with psychotic features have been observed in patients with an acute encephalitic onset of MS, but usually in combination with clear neurological signs. A recent epidemiological study into cases of MS first presenting to psychiatrists ${ }^{21}$ has revealed that physical symptoms and signs were almost always present when the patients complained of affective symptoms, but were often overlooked or misinterpreted. Furthermore, the fact that psychiatric morbidity is not increased before the onset of $M S^{11}$ or in patients with clinically isolated lesions, ${ }^{22}$ frequently the harbinger of $M S,{ }^{2324}$ argues against this possibility. The role of stressful events in precipitating relapses has also been debated, ${ }^{25}$ but at best this is unlikely to explain more than a minor part of the variance.

\section{Cognitive abnormalities}

The view that cognitive dysfunction is spared in the majority of patients with multiple sclerosis ${ }^{2627}$ has been firmly laid to rest. It is now accepted that $50-60 \%$ of those attending ${ }^{28}$ hospital and slightly fewer community based patients ${ }^{29}$ have evidence of cognitive impairment. Memory, attention and abstracting abilities are commonly impaired, with relative sparing of language functions. ${ }^{30-32}$ This pattern differs sharply from that encountered in Alzheimer's disease $\mathrm{e}^{33}$ and it is characteristic of diseases involving the white matter. The fact that cognitive decline in MS has a more subtle clinical presentation does not diminish its 
importance for those with impairment, who experience significantly more difficulties in their work, social contact, sex and activities of daily living, than those without. ${ }^{34}$

Evidence that cognitive impairment may be one of the earliest features of the illness, often predating the development of other neurological signs and symptoms, comes from studies of patients with clinically isolated lesions (optic neuritis, brain stem and spinal cord syndromes). While memory ${ }^{35}$ and attention ${ }^{36}$ are already impaired in these patients, often in the absence of neurological disability, little is known about the natural history of these deficits. A recent five year follow up of patients with clinically isolated lesions seen at the National Hospital ${ }^{9}$ has suggested that cognitive decline is closely linked to disease course. Thus whilst a deterioration in attention and memory functions had occurred in those who had entered a chronic progressive phase, there was little evidence of deterioration in those who had not developed further neurological symptoms. This is in keeping with the finding in patients with well established MS, of greater cognitive impairment when the course is chronic progressive rather than relapsing remitting. ${ }^{37}{ }^{38}$ However, adherence to disease type over time has been shown to be extremely variable $^{39}$ and it remains to be seen whether these changes will be paralleled by changes in the pattern of cognitive deterioration. The possibility that cognitive performance may fluctuate, together with other neurological features or in isolation as a result of the waxing and waning of brain lesions, ${ }^{40}$ also needs exploration.

An association between the degree of cognitive impairment and physical disability has been reported by some researchers ${ }^{41}$ but not by others, ${ }^{32}$ which is not difficult to understand if one considers that earlier studies had not taken into consideration the link between cognition and disease type. Even within a well characterised clinical group disability may result from neuropathological lesions that differ in site and evolution. Thus patients with a primary chronic progressive disease have significantly lower lesion load ${ }^{42}$ and less changeable MRI brain pathology ${ }^{40}$ than those with a secondary chronic progressive course. A more detailed clinical characterisation will therefore be necessary before the links between various disability indices can be unravelled.

As expected, the severity of cognitive impairment correlates with the extent of brain pathology shown by MRI. ${ }^{324344}$ Specific correlations between particular deficits and sites of pathology have however proved more elusive. This is due in part to the difficulties in assessing lesions quantitatively and in visualising certain brain structures (for example, hippocampal region) without lengthy scanning. It is also difficult to disentangle the effect of a given lesion when widespread pathology is present. This is further complicated by the fact that detectable abnormalities represent lesions in different stages of evolution, likely to cause variable degrees of functional disruption ${ }^{45}$ and that pathological processes not detectable by imaging may also be relevant. This is illustrated by the significant correlation between the degree of cognitive impairment and elevated $T 1$ relaxation times in normal appearing frontal white matter found in patients with early chronic progressive disease. $^{9}$

\section{Conclusion}

Psychiatric and cognitive abnormalities are common in MS and add considerably to the distress and disability. They are frequently overlooked, sometimes in an attempt to avoid further distress in patients already burdened with an incurable disease. This neglect is fortunately changing. Treatment of affective symptoms, following standard prac- tices, is effective in $M^{46}$ and should always be attempted. Prolonged neuropsychological examination is not necessary to document cognitive performance and brief screening procedures with a high degree of sensitivity have been developed. ${ }^{47}$ Such instruments should now be incorporated in all treatment trials, as part of the overall assessment of impact on disability. The management of cognitive deficits is more problematic, but useful rehabilitation strategies aimed at maximising skills are available. ${ }^{48}$

MARIA A RON ANTHONY FEINSTEIN

Institute of Neurology,

London, UK

1 Pratt RTC. An investigation of the psychiatric manifestations of disseminated sclerosis. J Neurol Neurosurg Psychiatry 1951;14:326-35.

Surridge $D$. An investigation into some psychiatric aspects of multiple sclerosis. B J Psychiatry 1969;115:749-64.

3 Minden SL, Orav J, Reich P. Depression in multiple sclerosis. Gen Hosp Psychiatry 1987;9:426-34.

4 Minden SL, Schiffer RB. Affective disorders in multiple sclerosis. Review and recommendations for clinical research. Arch Neurol 1990;47:98-104. 5 Schiffer RB, Wineman NM, Weitkamp LR. Association between bipolar affective disorder and multiple sclerosis. Am J Psychiatry 1986;143:94-5. 6 Joffe RT, Lippert GP, Gray TA, Sawa G, Horvath Z. Mood disorder and multiple sclerosis. Arch Neurol 1987;44:376-8.

7 Minden SL, Orav J, Schildkraut JJ. Hypomanic reactions to ACTH and prednisone treatment for multiple sclerosis. Neurology 1988;38:1631-4.

8 Dalos NP, Rabins PV, Brooks BR, O'Donell P. Disease activity and emotional state in multiple sclerosis. Ann Neurol 1983;13:573-7.

9 Feinstein A, Kartsounis L, Miller D, Youl B, Ron MA. Clinically isolated lesions of the type seen in multiple sclerosis followed up: a cognitive, psychiatric and MRI study. (in press).

10 Rabins PV, Brooks BR, O'Donell P, et al. Structural brain correlates of emotional disorder in multiple sclerosis. Brain 1986;109:585-97.

11 Ron MA, Logsdail SJ. Psychiatric morbidity in multiple sclerosis: a clinical and MRI study. Psychol Med 1989;19:887-95.

12 Schiffer RB, Barbigian HM. Behavioural disorders in multiple sclerosis, temporal lobe epilepsy and amyotrophic lateral sclerosis. An epidemiological study. Arch Neurol 1984;41:1067-9.

13 Joffe RT, Lippert GP, Gray TA, Sawa G, Horvath Z. Personal and family history of affective illness in patients with multiple sclerosis. $J$ Affect Diss 1987;12:63-5.

14 Cottrell SS, Wilson SAK. The affective symptomatology of disseminated sclerosis. J Neurol Psychopathol 1926;7:1-30.

15 Reischies FM, Baum K, Brau H, Hedde JP, Schwindt G. Cerebral magnetic resonance imaging findings in multiple sclerosis. Arch Neurol 1988; 45:1114-6.

16 Davison K, Bagley CR. Schizophrenia-like psychoses associated with organic disorder of the central nervous system: a review of the literature. In: Herrington RN, ed. Current problems in neuropsychiatry. Ashford, Kent: Headley, 1969:113-84.

17 Feinstein A, Ron MA. Psychosis associated with demonstrable brain disease. Psychol Med 1990;20:793-803.

18 Feinstein A, du Boulay G, Ron MA. Psychotic illness in multiple sclerosis: A clinical and MRI study. $\mathrm{Br} J$ Psychiatry. (in press).

19 Mathews WB. Multiple sclerosis presenting with acute remitting psychiatric symptoms. J Neurol, Neurosurg Psychiatry 1979;42:859-63.

20 Whitlock FA, Siskind MM. Depression as a major symptom of multiple sclerosis. J Neurol, Neurosurg Psychiatry 1980;43:861-5.

21 Skegg K, Corwin PA, Skegg DCG. How often is multiple sclerosis mistaken for a psychiatric disorder? Psychol Med 1988;18:733-6.

22 Logsdail SJ, Callanan MM, Ron MA. Psychiatric morbidity in patients with clinically isolated lesions of the type seen in multiple sclerosis: a clinical clinically isolated lesions of the type seen in mul
and MRI study. Psychol Med 1988;18:355-64.

23 Francis DA, Compston DAS, Batchelor JR, McDonald WI. A reassessment of the risk of multiple sclerosis developing in patients with optic neuritis after extended follow-up. J Neurol, Neurosurg Psychiatry 1987;50:758-65.

24 Miller DH, Ormerod IEC, Rudge P, Kendall BE, Moseley IF, McDonald WI. The early risk of multiple sclerosis following isolated acute syndromes of the brain stem and spinal cord. Ann Neurol 1989;26:635-9.

25 Warren S, Warren KG, Cockerill R. Emotional Stress and coping in multiple sclerosis exacerbations. Journal of Psychosomatic Research 1991;35(1): $37-47$.

26 Kurtzke JF, Beebe GW, Nagler B, Nefzgerb MD, Auth TL, Kurland LT. Studies on the natural history of multiple sclerosis. V. Longitudinal survival in young men. Arch Neurol 1970;22:215-25.

27 Kahana E, Leibowitz U, Alter M. Cerebral multiple sclerosis. Neurology 1971;21:1179-85

28 Peyser JM, Rao SM, LaRocca NG, Kaplan E. Guidelines for neuropsychological research in multiple sclerosis. Arch Neurol 1990;47:94-97.

29 Rao SM, Leo GL, Bernardin L, Unverzagt MS. Cognitive dysfunction in multiple sclerosis. I. Frequency, patterns and prediction. Neurology 1991;41:685-91.

30 Rao SM, Hammeke TA, McQuillen MP, Khatri Bo, Lloyd D. Memory disturbance in chronic-progressive multiple sclerosis. Arch Neurol 1984; 41:625-31.

31 Franklin GM, Nelson LM, Filey CM, Heaton RK. Cognitive loss in multiple sclerosis. Case reports and review of the literature. Arch Neurol 1989;46:162-7.

32 Ron MA, Callanan MM, Warrington EK. Cognitive abnormalities in multiple sclerosis: a psychometric and MRI study. Psychol Med 1991; 21:59-68.

33 Filley CM, Heaton RK, Nelson LM, Burks JS, Franklin TG. A comparison of dementia in Alzheimer's disease and multiple sclerosis. Arch Neurol 1989;46:157-61. 
34 Rao SM, Leo GJ, Ellington L, Nauertz T, Bernardin L, Unverzagt F. Cognitive dysfunction in multiple sclerosis. II. Impact on employmen and social functioning. Neurology 1991;41:692-6.

35 Lyon-Caen $\mathrm{O}$, Jouvent $\mathrm{R}$, Hauser $\mathrm{S}$, et al. Cognitive dysfunction in recent onset demyelinating disease. Arch Neurol 1986;43:1138-41.

36 Callanan MM, Logsdail SJ, Ron MA, Warrington EK. Cognitive impairment in patients with clinically isolated lesions of the type seen in MS. Brain in patients with cling

37 Heaton RK, Nelson LM, Thompson DS, Burk JS, Franklin GM. Neuropsychological findings in relapsing-remitting and chronic-progressive psychological findings in relapsing-remitting and chronic-progressive multiple scle

38 Rao SM, Hammeke TA, Speech TJ. Wisconsin Card Test performance in relapsing-remitting and chronic-progressive multiple sclerosis. Journal of Consulting and Clinical Psychology 1987;55:263-5.

39 Goodkin RE, Hertsgaard D, Rudick RA. Exacerbation rates and adherence to disease type in a prospectively followed up population with multiple sclerosis. Arch Neurol 1990;46:1107-12.

40 Thompson AJ, Kermode AG, Wicks D, et al. Major differences in the dynamics of primary and secondary multiple sclerosis. Ann Neurol 1991;29:53-62.

41 Stenager E, Knudsen L, Jensen K. Correlation of Beck depression inventory score, Kurtzke disability status and cognitive functioning in multiple sclerosis. In: Jensen K, Knudsen L, Stenager E, Grant I, eds. Current problems in neurology. 10: mental disorders and cognitive deficits in multiple sclerosis. London: John Libbey, 1989:147-52.

42 Thompson AJ, Kermode AG, MacManus D, et al. Patterns of disease activity in multiple sclerosis: a clinical and magnetic resonance study. $B M J$ 1990;300:631-4.

43 Franklin GM, Heaton RK, Nelson LM, Filley CM, Seibert C. Correlations of neuropsychological and MRI findings in chronic-progressive multiple sclerosis. Neurology 1988;38:1826-9.

44 Rao SM, Leo GJ, Haughton VM, St. Aubin-Faubert P, Bernardin L. Correlation of magnetic resonance imaging with neuropsychological testing in multiple sclerosis. Neurology 1989;39:161-6.

45 Kermode AG, Thompson AJ, Tofts P, et al. Breakdown of the blood brain barrier precedes symptoms and other MRI signs of new lesions in multiple barrier precedes symptoms and other MRI signs of new lesions in multiple

46 Schiffer RB, Wineman NM. Antidepressant pharmacotherapy with multiple sclerosis. Am J Psychiatry 1990;147:1493-7.

47 Beatty WW, Goodkin DE. Screening for cognitive impairment in multiple sclerosis. An evaluation of the mini-mental state. Arch Neurol 1990; 47:297-301.

48 LaRocca NG. A rehabilitation perspective. In: Rao SM, ed. Neurobehavioural aspects of multiple sclerosis. Oxford University Press: New York, 1990.

\section{Neurological stamp}

\section{Andreas Vesalius (1514-64)}

Vesalius, creator of modern human anatomy, was born in Brussels and initially studied in Paris where he was taught Galenic anatomy. He was banished from France for dissecting corpses from old cemeteries and gallows. Vesalius graduated with an MD from Padua in 1537 and the following day was appointed Professor.

At first he followed the dogmatic teaching of Galen but soon based lectures on his own observations. His teachings and book De Humani Corporis Fabrica Libri Septum, published in 1543, replaced traditional anatomy. In the Fabrica Vesalius also enlarged and amended the work of Galen. The concepts of Galen, who had only dissected animals, had dominated medical teaching for 1500 years. The Fabrica contained some magnificent plates, particularly of muscles, and included excellent descriptions of the brain and nervous system. Vesalius, who had a hostile reception from the Galenists, gave up teaching to become physician to Charles V of Spain and 12 years later to his successor Philip II. Shipwrecked off Greece while homeward bound after a pilgrimage to Jerusalem he died at the age of 50 .

In 1964 Belgium commemorated the 400th anniversary of his death with a postage stamp. (Stanley Gibbons No 1884, Scott No 570). The illustration, a woodcut from the Fabrica, displays muscular details of the arm.

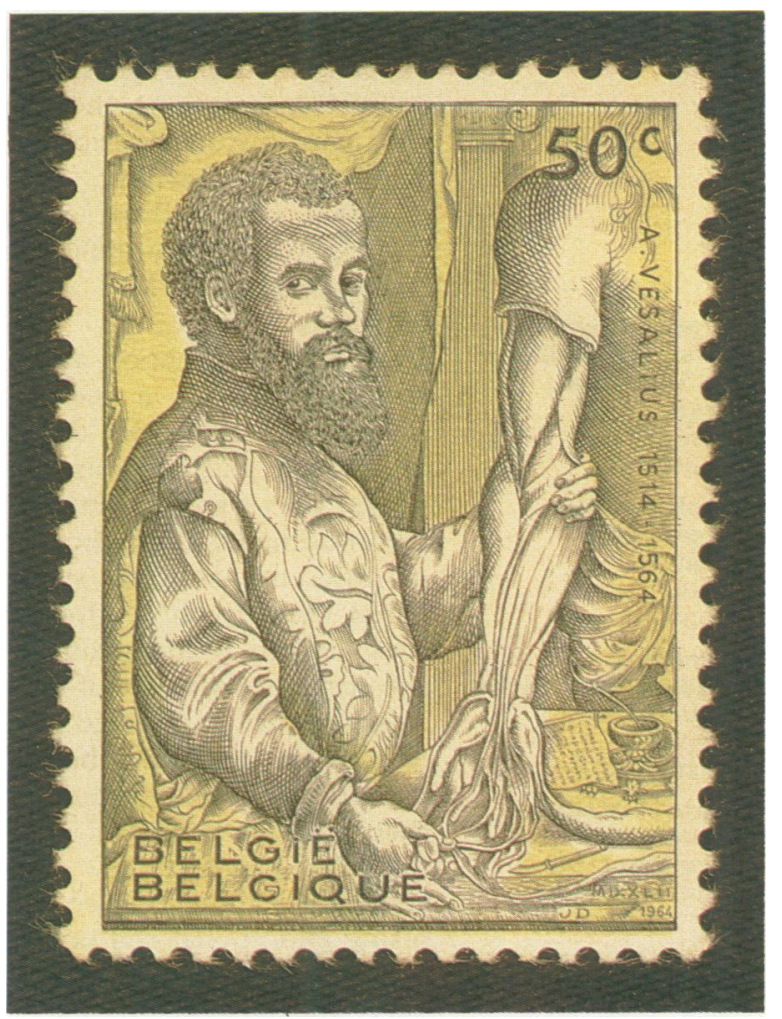

